\title{
Dyeing Fabrics by Using Extracts from Mulberry Branch/Trunk 1. Dyeability and Fluorescence Property
}

\author{
Thị Kim Thu Nguyễn, Akihiro Kuroda, Hiroshi Urakawa, Hidekazu Yasunaga* \\ Department of Fibre Science and Engineering, Kyoto Institute of Technology, Kyoto, Japan \\ Email: *yasunaga@kit.ac.jp
}

How to cite this paper: Nguyễn, T.K.T., Kuroda, A., Urakawa, H. and Yasunaga, H. (2017) Dyeing Fabrics by Using Extracts from Mulberry Branch/Trunk 1. Dyeability and Fluorescence Property. American Journal of Plant Sciences, 8, 1888-1903. https://doi.org/10.4236/ajps.2017.88128

Received: June 9, 2017

Accepted: July 21, 2017

Published: July 24, 2017

Copyright $\odot 2017$ by authors and Scientific Research Publishing Inc. This work is licensed under the Creative Commons Attribution-NonCommercial International License (CC BY-NC 4.0). http://creativecommons.org/licenses/by-nc/4.0/

\begin{abstract}
The dyeing of wool, silk, cotton, ramie, nylon, acrylic and polyester fabric by using the extracts from mulberry branches and trunks was tried and the dyeability was studied. While the dyeability of the ethanol-extracts from mulberry is low, that of the water-extracts is high for wool, nylon and silk fabrics. They are dyed brownish and yellowish colours. The obtained colours depend on the extracts concentration in the dye solution, dyeing time, dye solution $\mathrm{pH}$ and dyeing temperature. Wool, nylon and silk fabrics are dyed deeper with an increase in the dyeing temperature. The mulberry extracts show fluorescence and reducing property. The results indicate that the mulberry extracts contain flavonols such as morin, kaempferol or quercetin, which form complexes with $\mathrm{Al}^{3+}$ and show fluorescence. The wool treated with the mulberry extracts or $\mathrm{AlCl}_{3} /$ mulberry extracts shows fluorescence with ultraviolet light irradiation.
\end{abstract}

\section{Keywords}

Mulberry Branch, Mulberry Trunk, Extracts, Dyeing, Fluorescence, Reductant, Sustainable Dyestuff Material

\section{Introduction}

Mulberry (Morus) trees belonging to the family of Moraceae are important plants that have been used for sericulture to produce silk fibres as it is generally well known. The leaves, fruits and root barks of mulberry trees have long been

*The part of the data of this study were presented by the authors at the Annual Meeting of The Textile Machinery Society Japan on 5-6 June (2015)at Osaka, Japan (Proceedings: 68, 100-101), the 13th Asian Textile Conferenceon 3-6 November (2015) at Geelong, Australia (Proceedings ID: 3(C), 1007-1009), Kuroda, A. (2016) Master Thesis, Kyoto Institute of Technology, Kyoto, Japan, 3 rd International Symposium on Advances in Sustainable Polymers on 4-6 August (2016) at Kyoto, Japanand 9 th International Conference onFiber and Polymer Biotechnology on 7-9 September (2016) at Osaka, Japan. 
used widely in the field of silk production, food industries and medicines [1]. On the other hand, while the mulberry branches and trunks have been used for wood products and paper to a limited extent [1], the great mass of them are treated as industrial wastes. However, the peels of black mulberry (Morus nigra) were used to, for example, colour woods [2]. Pigment ingredients were extracted from the peels with water in an ultrasonic bath and wood samples were treated by immersing into the solution containing the extracts. The colours (absolute colour values) obtained in the study were not described in the article, and it is estimated from the change in $\Delta L^{*}, \Delta a^{*}$ and $\Delta b^{*}$ values that the wood may be coloured brown.

The exploitation and development of novel sustainable dyestuff materials and the effective utilization of industrial wastes are very important to establish a sustainable society and achieve environmental preservation. Under such a situation, the authors tried to dye fabrics with mulberry extracts in the study. The dyeing of fabrics by using a dyestuff obtained from waste mulberry branches and trunks has not been studied aiming to apply the dyestuff to industrial uses. If a useful dyestuff could be obtained from the mulberry extracts, it is expected that the technique will contribute to the efficient use of mulberry wastes. The characteristics of mulberry trees are as follows: 1) the photosynthetic rate and the growing rate of tree are high [3], 2) useful parts are many in the whole plant, 3) ecological $[1], 4)$ mulberry is generally grown without pesticides and so on. Therefore, it is a great advantage to take dyestuffs from mulberry branches and trunks from the viewpoints of productivity, sustainability, ecology and safety. It can be said that the mulberry branch dyestuff could be a useful dyestuff in the future.

In the study, the dyeability of the extracts from mulberry branches and trunks for natural and chemical fibres such as wool, silk, cotton, ramie, nylon, acrylic and polyester fabrics was investigated as a first step. The properties of the mulberry extracts were also examined.

\section{Experimental}

\subsection{Extraction from Mulberry Trees}

The mulberry branches and trunks (Morus australis and Morus Ihou) were obtained from the mulberry field of Kyoto Institute of Technology. The woods with barks were crashed by a mill (Osaka Chemical Wonder Blender WB-1) and were extracted with ethanol (purity: $99.5 \%$ ) at $78^{\circ} \mathrm{C}$ or distilled water at $100^{\circ} \mathrm{C}$ for $4 \mathrm{~h}$. The extracts were concentrated and dried. The dried mulberry extracts were ground into powder.

\subsection{Fabrics}

The wool fabric (tropical, Shikisensha), silk fabric (Kinu Habutai, Shikisensha, basis weight: $52.5 \mathrm{~g} \cdot \mathrm{m}^{-2}$, fabric count: $135 \times 98$ per inch, plain weave), cotton fabric (broad, Shikisensha), ramie fabric (broad, Shikisensha), nylon fabric (tafta, Shikisensha, basis weight: $60.4 \mathrm{~g} \cdot \mathrm{m}^{-2}$, fabric count: $108 \times 82$ per inch, plain weave), acrylic fabric (muslin, Shikisensha) and polyester fabric (tafta, Shikisen- 
sha, basis weight: $71.8 \mathrm{~g} \cdot \mathrm{m}^{-2}$, fabric count: $120 \times 90$ per inch, plain weave) were cut into $5 \mathrm{~cm}$ squares and used for the dyeing experiments.

\subsection{Dyeing}

The oily mulberry extracts $(0.50 \mathrm{~g})$, which were obtained from the extraction with ethanol, were dissolved into $49.5 \mathrm{~g}$ of ethanol/distilled water mixed solvent (1:1 of mass ratio). Wool fabric sample was immersed first into distilled water at room temperature (RT) for $10 \mathrm{~s}$ and then into the mulberry extracts solution at $40^{\circ} \mathrm{C}$ for $3 \mathrm{~h}$. The dyebath was shaken at 80 strokes per minute. The powder mulberry extracts, which were obtained from the extraction with distilled water, were dissolved into distilled water to prepare $2.0 \mathrm{wt} \%$ solution. Each of the fabric samples was immersed first into distilled water at RT for $10 \mathrm{~s}$ and then into the mulberry extracts solution at fixed temperature $\left(30^{\circ} \mathrm{C}-90^{\circ} \mathrm{C}\right)$ for $3 \mathrm{~h}$. The dyebath was shaken at 80 strokes per minute. The liquor ratios were 179:1 for silk, 66.0:1 for wool, 90.6:1 for cotton, 80.1:1 for ramie, 160:1 for nylon, 108:1 for acrylic and 157:1 for polyester. Each of the fabric was washed with $50 \mathrm{ml}$ of 2.0 wt $\%$ marseille soup solution at $40^{\circ} \mathrm{C}$ for $10 \mathrm{~min}$, rinsed with $100 \mathrm{ml}$ of distilled water at $40^{\circ} \mathrm{C}$ for $5 \mathrm{~min}$ twice and air-dried.

\subsection{Colour Measurements}

The obtained colour of the fabric samples was measured by using a Konica Minolta CM-2600d spectrocolourimeter and the resulting colour was expressed in $L^{\star} a^{*} b^{\star}$ standard colourimetric system (CIE 1976). The colour measurements were made employing CIE standard illuminant $\mathrm{D}_{65}, 10^{\circ}$-view angle and SCI (specular component included) mode. All the reflected lights from the sample including the regular reflection are integrated under the SCI mode. The $a^{*}$ and $b^{*}$ are the chromaticity coordinates, and $L^{*}$ is the lightness index in the $L^{*} a^{*} b^{*}$ system. The positive values of $a^{*}$ indicate reddish colours and the negative values of that indicate greenish ones, and the positive values of $b^{\star}$ indicate yellowish and the negative values indicate bluish. The $C^{*}$ is the chroma calculated as $C^{*}=$ $\left\{\left(a^{*}\right)^{2}+\left(b^{\star}\right)^{2}\right\}^{1 / 2}[4][5]$.

\subsection{Ultraviolet-Visible Absorption Spectrophotometry and Fluorescence Spectroscopy}

The measurements of the ultraviolet-visible (UV-Vis) light absorption spectra for the mulberry extracts aqueous solutions were made by a Hitachi U-3900H spectrophotometer at RT. The sample solutions were prepared by dissolving mulberry extracts powders into freshly distilled water. Acidic or basic mulberry extracts solution was prepared by dissolving the powder into $2.0 \times 10^{-2} \mathrm{M}$ citric acid aqueous solution or $1.0 \mathrm{M} \mathrm{Na}_{2} \mathrm{CO}_{3} / \mathrm{NaHCO}_{3}$ aqueous solution, respectively. All of the sample aqueous solutions were measured at RT.

The fluorescence spectra of the mulberry extracts solution samples were measured by a JASCO FP-6500 fluorescence spectrophotometer at RT. The mulberry extracts powder $\left(1.0 \times 10^{-2} \mathrm{wt} \%\right)$ or the powder $\left(1.0 \times 10^{-2} \mathrm{wt} \%\right)$ and 
$\mathrm{AlCl}_{3}(0.050 \mathrm{M})$ were dissolved into freshly distilled water to prepare solutions.

\subsection{Reducibility of Mulberry Extracts}

As one of the evaluation techniques of the reducibility of mulberry extracts, the free radical scavenging method using 1,1-diphenyl-2-picrylhydrazyl radical (DPPH) was adopted. The DPPH method is a common antioxidant assay widely used [6]. When a reductant reacts with $\mathrm{DPPH}$, the DPPH radical form turns into a protonated (non-radical) form and the absorbance of a signal of DPPH solution spectrum decreases. The slope of the relationship between the concentration of a reductant and the absorbance is associated with the reducibility. The negative steeper slope corresponds to higher radical scavenging ability, that is, reducibility. DPPH ( $M_{\mathrm{w}}=394.32$, Tokyo Chemical Industry), 2-( $N$-morpholino) ethane-sulfonic acid (MES, $M_{\mathrm{w}}=213.25$, Nacalai Tesque (NT)) and DL- $\alpha$-tocopherol $\left(M_{\mathrm{w}}=430.71, \mathrm{NT}\right)$ were used without further purification. MES was dissolved into freshly distilled water and $0.1 \mathrm{M} \mathrm{NaOH}$ aqueous solution $\left(7.14 \times 10^{-5}\right.$ $\mathrm{M}, \mathrm{pH}=6.0)$ and DPPH was dissolved into ethanol $(250 \mu \mathrm{M})$. The mulberry extracts powder was dissolved into freshly distilled water and the sample aqueous solutions with each concentration were prepared. Ethanol (42.2 g) was added into $49.0 \mathrm{~g}$ of the each mulberry extracts aqueous solution. DL- $\alpha$-tocopherol was dissolved into ethanol and the solutions with each concentration were prepared. The MES solution (1.0 g) and DPPH solution (7.8 g) were mixed with each of the mulberry extracts or DL- $\alpha$-tocopherol solution sample (91.2 g) and were stirred for $20 \mathrm{~min}$ at $23^{\circ} \mathrm{C}$ in the dark. The UV-Vis absorption spectra for sample solutions were measured by a Hitachi $\mathrm{U}-3900 \mathrm{H}$ spectrophotometer at RT. The absorbance at $520 \mathrm{~nm}\left(A_{520}\right)$ was plotted against the sample concentration $(c)$ and the index of reducibility $\left(R_{\mathrm{AC}}\right)$ was estimated from the slope. $R_{\mathrm{AC}}$ is determined from the absolute value of the slope.

\section{Results and Discussion}

\subsection{Dyeability of Mulberry Extracts}

Orange oily material was obtained by the extraction from mulberry branches and trunks with ethanol. The mulberry ethanol-extracts are not soluble in water and were used as ethanol/water mixed solution for the dyeing experiment. The result shows that the colour of wool fabric turns very pale yellow by the treatment with the ethanol-extracts solution. The $L^{\star}$ of wool fabric changes from 87.6 to 85.6 by the treatment and those of the $a^{*}, b^{*}$ are from $-0.260,13.1$ to -0.480 , 15.7 , respectively. The changes in the colour values are very little. It can be said that the dyeability of the mulberry ethanol-extracts for wool is low.

On the other hand, brown powders were obtained by the extraction with water. The yield of the dry powder from the branches and trunks is $8.74 \%$ in mass. It was found that wool is dyed with the mulberry water-extracts aqueous solution unlike the ethanol-extracts solution. Then, the dyeability of the mulberry extracts for silk, cotton, ramie, nylon, acrylic and polyester fabric in addition to 
wool was examined. Only the mulberry water-extracts were used in the subsequent studies. The results show that acrylic and polyester are not dyed at all, cotton and ramie are dyed a little (actually almost not), whereas silk and nylon are dyed with the mulberry extracts, as well as wool. The dyeing results are summarised in Table 1 . And the photographs of the wool, silk and nylon fabrics before and after the treatment with the mulberry extracts are shown Figure 1. The wool is dyed light yellowish ocher, silk is dyed yellowish brown and nylon is dyed vivid yellow as shown in Figure 1 . The $L^{*}$ of the wool dyed by the mulberry extracts at $40^{\circ} \mathrm{C}$ is 81.8 , that of the silk is 82.2 and that of the nylon is 86.5 as given in Table 1. The $b^{*}$ of the wool, silk and nylon is 27.7, 25.8 and 43.3, respectively. These $b^{\star}$ values are high. The $a^{*}$ values of wool and nylon are small

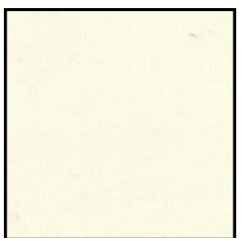

(a)

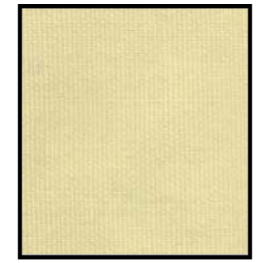

(d)

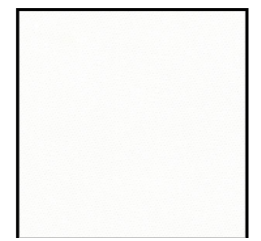

(b)

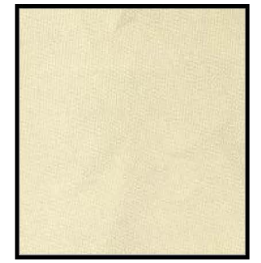

(e)

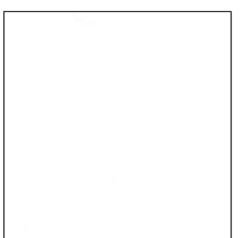

(c)

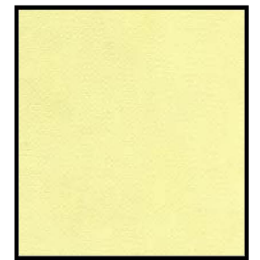

(f)

Figure 1. Photographs of the wool (a) and (d), silk (b) and (e) and nylon (c) and (f) fabrics before (a)-(c) and after (d)-(f) the dyeing with mulberry extracts solution. Conc. of mulberry extracts: $2.0 \mathrm{wt} \%$, dyeing temperature: $40^{\circ} \mathrm{C}$, dyeing time: $3 \mathrm{~h}, \mathrm{pH}$ : 6.5 .

Table 1. The colour values for wool, silk, cotton, ramie, nylon, acrylic and polyester fabrics before and after the treatment with mulberry extracts aqueous solution. Conc. of mulberry extracts: $2.0 \mathrm{wt} \%$, dyeing temperature: $40^{\circ} \mathrm{C}$, dyeing time: $3 \mathrm{~h}, \mathrm{pH}$ : 6.5 .

\begin{tabular}{|c|c|c|c|c|c|c|c|c|}
\hline \multirow[t]{2}{*}{ Sample } & \multicolumn{2}{|c|}{ Wool } & \multicolumn{2}{|c|}{ Silk } & \multicolumn{2}{|c|}{ Cotton } & \multicolumn{2}{|c|}{ Ramie } \\
\hline & initial & treated & initial & treated & initial & treated & initial & treated \\
\hline$L^{*}$ & 87.6 & 81.8 & 95.7 & 82.2 & 95.2 & 90.6 & 95.1 & 89.4 \\
\hline$a^{*}$ & -0.260 & -1.95 & -0.0926 & 2.41 & 0.00180 & 1.92 & 0.101 & 2.03 \\
\hline$b^{*}$ & 13.1 & 27.7 & 2.45 & 25.8 & 2.45 & 8.49 & 2.43 & 9.35 \\
\hline \multirow[t]{3}{*}{$C^{*}$} & 12.5 & 27.8 & 2.45 & 25.9 & 2.45 & 8.71 & 2.43 & 9.57 \\
\hline & \multicolumn{2}{|c|}{ Nylon } & \multicolumn{2}{|c|}{ Acrylic } & \multicolumn{3}{|c|}{ Polyester } & \\
\hline & initial & treated & initial & treated & ini & & treated & \\
\hline$L^{*}$ & 95.1 & 86.5 & 93.5 & 93.3 & 95 & & 95.3 & \\
\hline$a^{*}$ & -1.14 & -4.94 & -0.661 & -0.672 & -0 & & -0.328 & \\
\hline$b^{*}$ & 7.75 & 43.3 & 6.52 & 6.89 & 2. & & 2.52 & \\
\hline$C^{*}$ & 7.83 & 43.5 & 6.55 & 6.92 & 2. & & 2.54 & \\
\hline
\end{tabular}


but negative, which means the colours include a green component. The effective dyeing results were obtained for wool, silk and nylon samples and it is concluded that the mulberry extracts dye the three kinds of fibres. The dyeable three fibres have charges and amide bonds in their molecular chains in common. The results show that the dyeabilities are due to such the chemical characteristics and higher ordered structures of the fibres. In fact, the fibres are dyed with acid dyes and their dyeability against a sort of dye molecules is very similar.

The dependence of the dyeability of wool on the mulberry extracts concentration or the dyeing time was also examined [7]. The results show that the higher dyeability (lower $L^{*}$ and higher $b^{*}$ values) is obtained by using higher concentration of the mulberry extracts and with longer dyeing time, as expected.

The colour fastness for the fabrics dyed by the mulberry extracts to washing and light are studied by the authors and will be reported.

\subsection{Dyeability According to Solution $\mathrm{pH}$}

It is well known that the colour of natural pigments change with $\mathrm{pH}$ [8] or the copigmentation [9]. The dyeability of wool, silk, and nylon is affected by $\mathrm{pH}$ in the case of the dyeing with acid dyes [10]. Then, it is interesting to investigate the $\mathrm{pH}$ effect of the mulberry extracts dyeing solution on the dyeability. The lower $\mathrm{pH}$ aqueous treatment solution was prepared with the mulberry extracts and citric acid $\left(2.0 \times 10^{-2} \mathrm{M}\right)$. The medium $\mathrm{pH}$ solution was prepared with only the mulberry extracts. The higher one was prepared with the mulberry extracts and $\mathrm{Na}_{2} \mathrm{CO}_{3} / \mathrm{NaHCO}_{3}(1.0 \mathrm{M})$. Figure 2 shows the photographs of the wool fabrics treated with the mulberry extracts solutions of each of the $\mathrm{pH}(2.5,6.5$ and 9.5). The colour of the wool dyed at $\mathrm{pH}=2.5$ is more yellowish as compared with that of the sample at $\mathrm{pH}=6.5$ and that at $\mathrm{pH}=9.5$ is a little reddish. The $L^{*}$ and $b^{*}$ values of the sample at $\mathrm{pH}=2.5$ (83.0 and 36.7, respectively) are higher and those at $\mathrm{pH}=9.5$ (80.7 and 20.5, respectively) are lower than those at $\mathrm{pH}=$ 6.5 (81.8 and 27.7, respectively). The results show that the wool is dyed slightly yellowish at lower $\mathrm{pH}$ and slightly reddish at higher $\mathrm{pH}$ by the mulberry extracts.

It is expected that the $\mathrm{pH}$ dependence of the obtained colour of the dyed wool may be caused by the change in colour of the extracts in the dyeing solution. Figure 3 shows the UV-visible absorption spectra of mulberry aqueous solution, of which $\mathrm{pH}$ are 2.5, 6.5 and 9.5. While the spectrum for the solution of $\mathrm{pH}=2.5$ is similar to that of $\mathrm{pH}=6.5$, the intensity of the acidic solution is lower than that of the neutral solution and their spectrumshapes in the region between 360 to $460 \mathrm{~nm}$ are different. A slight difference in the colour between the neutral and acidic solutions is recognised. On the other hand, considerable difference in the spectrum shape between the solutions of $\mathrm{pH}=6.5$ and 9.5 is observed, and especially it is detected in the region from 280 to $600 \mathrm{~nm}$. In fact, the colour of the basic solution is different from that of the neutral one. The colour of the natural pigments such as anthocyanins (including anthocyanidins) changes according to $\mathrm{pH}$ [11] [12]. The results suggest that the colour change of pigments contained in the mulberry extracts with the solution $\mathrm{pH}$ induces the different colours of 


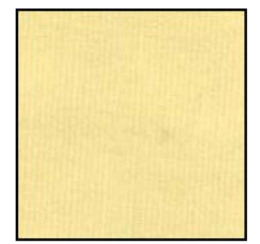

(a)

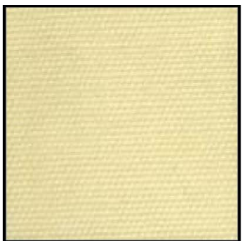

(b)

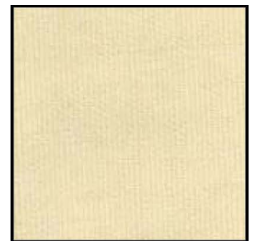

(c)

Figure 2. Photographs of the wool fabrics dyed with mulberry extracts solution. Solution $\mathrm{pH}=2.5$ (a); 6.5 (b) and 9.5 (c). Conc. of mulberry extracts: $2.0 \mathrm{wt} \%$, dyeing temperature: $40^{\circ} \mathrm{C}$, dyeing time: $3 \mathrm{~h}$.

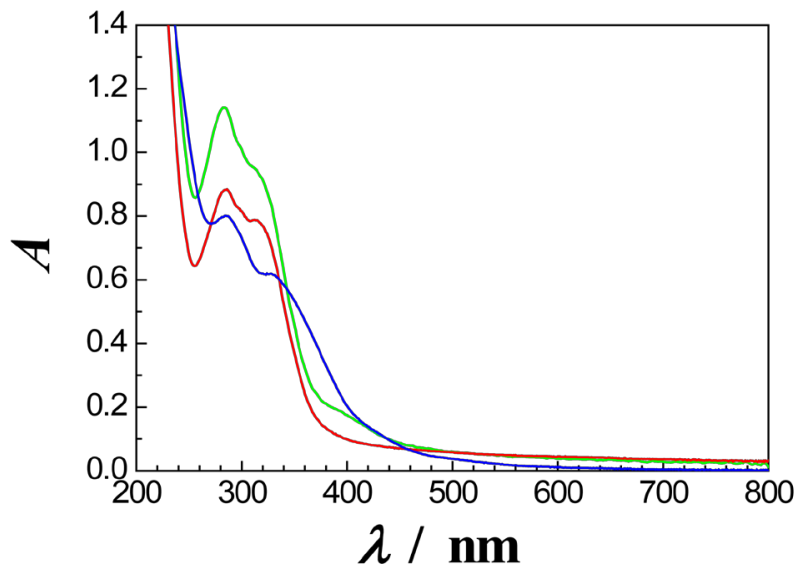

Figure 3. Absorption spectra for mulberry extracts aqueous solutions. Solution $\mathrm{pH}=2.5$ (red line), 6.5 (green line) and 9.5 (blue line). Conc. of mulberry extracts for each solution: $2.0 \times 10^{-2} \mathrm{wt} \%$.

dyed wool. The changed chemical structure of pigments in the dyeing solution according to the $\mathrm{pH}$ may be fixed after the treatment. As reported and discussed at $\$ 3.4$, the mulberry extracts contain flavonoids, which show reducibility. The colour of such the flavonoids changes under basic condition [13] and turns into duller and/or darker one. If the $\mathrm{pH}$ effect on the charge and structures of wool keratin would dominate the dyeability, the dyeing results must differ from those obtained. The negative charge becomes predominant for keratin protein at higher $\mathrm{pH}$ and the positive one is increased at lower $\mathrm{pH}$. If the dye molecules would be chiefly anionic, lower $\mathrm{pH}$ of the solution is suitable for higher dyeability and if they would be cationic, higher $\mathrm{pH}$ is dye suitable. Only one of the dyeability obtained at lower or higher $\mathrm{pH}$ should be increased if the charge of keratin would primarily control the colour. Therefore, it concludes that the $\mathrm{pH}$ dependence of the obtained colour of the wool may be due principally to the colour change of the pigments.

\subsection{Dyeability According to Dyeing Temperature}

It is also generally well known that the dyeing results are significantly influenced by the dyeing temperature [14]. Therefore, it is important to investigate the temperature dependence of the dyeability for the mulberry extracts. The dyeability of wool, silk and nylon using the mulberry extracts was examined. 
The change in the resulting colours of dyed fabrics depending upon dyeing temperature was observed. The colours of the three kinds of dyed fabrics become commonly more brownish and darker with an increase in temperature. The deepest colours for dyed wool, silk and nylon are obtained at $90^{\circ} \mathrm{C}$. The obtained colour values are summarised in Table 2 and the sequences of the values ac-

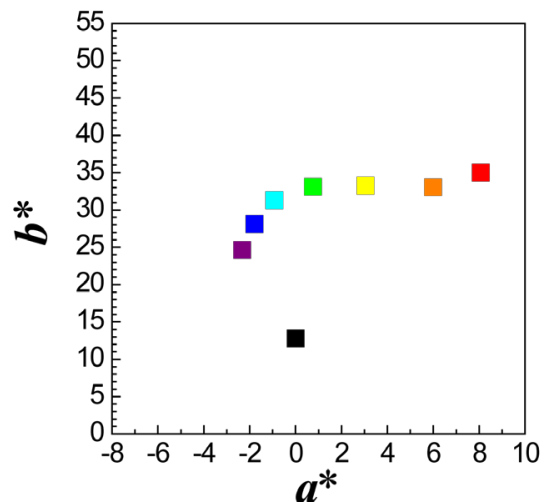

(a)

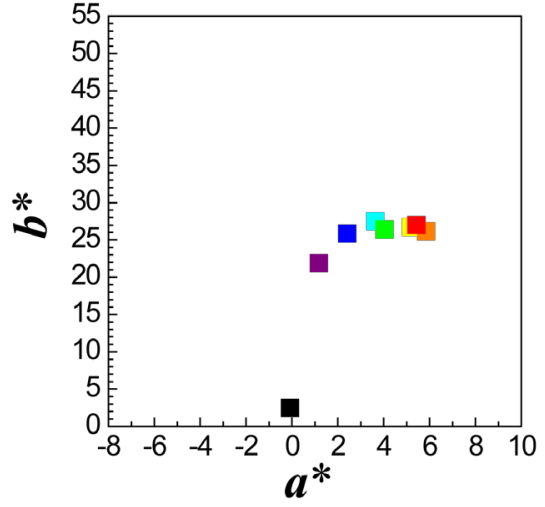

(c)

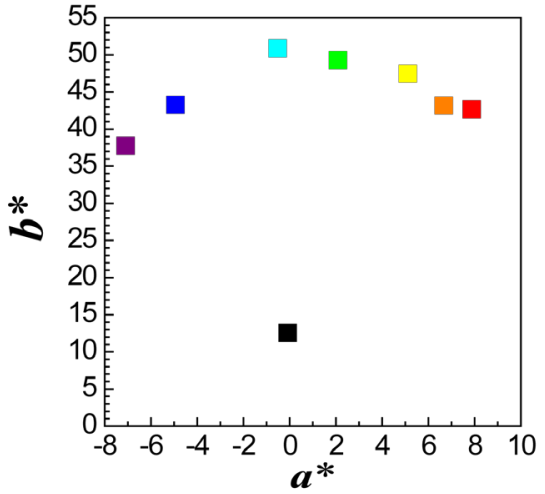

(e)

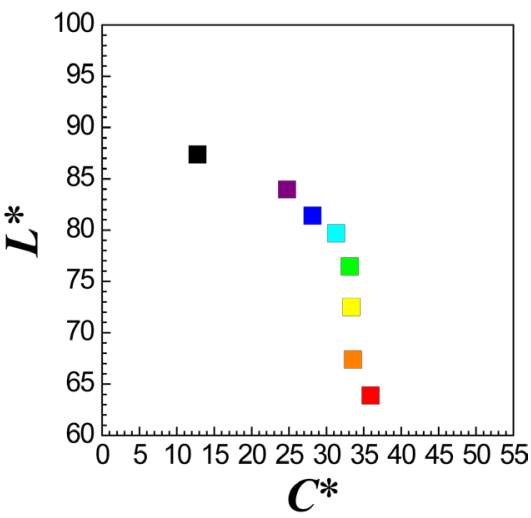

(b)

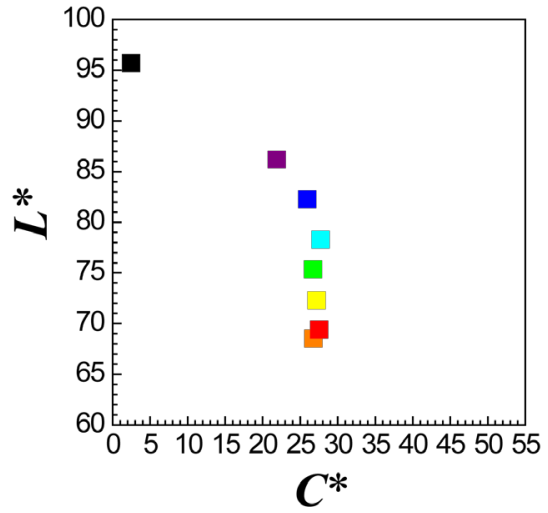

(d)

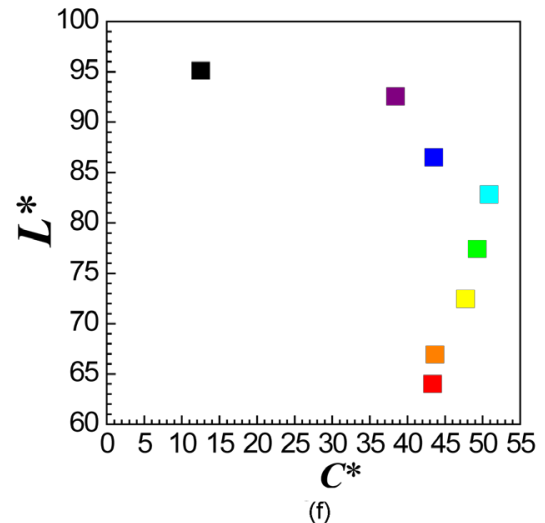

Figure 4. Colour measurement results shown as $a^{*}-b^{*}$ and $C^{*}-L^{*}$ relationships for wool (a) and (b); silk (c) and (d) and nylon (e) and (f) fabrics dyed with mulberry extracts solution at each temperature. Samples before dyed: (black symbols), samples dyed at $30^{\circ} \mathrm{C}$ (purple symbols), $40^{\circ} \mathrm{C}$ (blue symbols), $50^{\circ} \mathrm{C}$ (light blue symbols), $60^{\circ} \mathrm{C}$ (green symbols), $70^{\circ} \mathrm{C}$ (yellow symbols), $80^{\circ} \mathrm{C}$ (orange symbols) and $90^{\circ} \mathrm{C}$ (red symbols). Conc. of mulberry extracts: $2.0 \mathrm{wt} \%$, dyeing time: $3 \mathrm{~h}, \mathrm{pH}: 6.5$. 
cording to the dyeing temperature are shown in Figure 4. The results show that the $a^{*}$ of dyed wool and nylon shifts first to lower and then higher with an increase in the dyeing temperature, whereas that of silk increases monotonously with the temperature. The $b^{\star}$ of dyed wool and silk increases monotonously with the temperature, meanwhile that of nylon increases once with the temperature and decreases at over $50^{\circ} \mathrm{C}$. The $L^{\star}$ of the three kinds of fibres decreases with increasing temperature. The obtained colours for the three kinds of fibres can be said to depend strongly upon the dyeing temperature and their dyeability is highest at $90^{\circ} \mathrm{C}$. However, the hue or chromaticity of dyed colour for nylon fabric changes from yellow to yellowish brown with increasing dyeing temperature.

The amount of dyestuffs adsorbed onto fibres, their distribution in fibre materials, the sort and the composition of pigments adsorbed and so on are strongly controlled by dyeing temperature and then the dyeing results (obtained colours) are associated with them. If the mulberry extracts contain pigments, which work as a reductant, the colour of the pigment could be changed by oxidation. The oxidation reaction of the pigments may be promoted by heating. Therefore, there is a possibility that the higher temperature during the dyeing accelerates the oxidation of the pigments of the extracts. However, the change in the colour of the dyeing solution was not observed even at higher temperatures. Figure 5 shows the absorption spectra for the mulberry extracts aqueous solution before heated and $3 \mathrm{~h}$ after heated. Both of the spectra are very similar. The results show that the pigments contained in the mulberry extracts do not change chemically during the dyeing at higher temperatures and the differences in the resulting fabric colour may be induced by an another mechanism. The dyeing rate increases with increasing temperature within a certain dyeing time [14]. It is estimated that the increase in the diffusion rate of pigment molecules in wool, silk and nylon fibres might contribute to deepen the dyeing colours. Further investi gation is needed to clarify the mechanism.

Table 2. The colour values for wool, silk and nylon fabrics dyed with mulberry extracts solution. Conc. of mulberry extracts: $2.0 \mathrm{wt} \%$, dyeing temperature: $30-90^{\circ} \mathrm{C}$, dyeing time: 3 h, pH: 6.5 .

\begin{tabular}{cccccccccc}
\hline Sample & \multicolumn{3}{c}{ Wool } & \multicolumn{3}{c}{ Silk } & \multicolumn{3}{c}{ Nylon } \\
\hline & $L^{*}$ & $a^{*}$ & $b^{*}$ & $L^{*}$ & $a^{*}$ & $b^{*}$ & $L^{*}$ & $a^{*}$ & $b^{*}$ \\
\hline Initial & 87.6 & -0.26 & 13.1 & 95.7 & -0.09 & 2.45 & 95.1 & -1.14 & 7.75 \\
$30^{\circ} \mathrm{C}$ & 84.0 & -2.32 & 24.6 & 86.2 & 1.18 & 21.9 & 92.5 & -7.09 & 37.7 \\
$40^{\circ} \mathrm{C}$ & 81.8 & -1.95 & 27.7 & 82.2 & 2.41 & 25.8 & 86.5 & -4.94 & 43.3 \\
$50^{\circ} \mathrm{C}$ & 80.1 & -1.14 & 30.8 & 78.3 & 3.64 & 27.5 & 82.8 & -0.39 & 50.9 \\
$60^{\circ} \mathrm{C}$ & 76.9 & 0.55 & 32.8 & 75.3 & 4.04 & 26.4 & 77.4 & 2.09 & 49.2 \\
$70^{\circ} \mathrm{C}$ & 72.9 & 2.88 & 33.0 & 72.3 & 5.19 & 26.7 & 72.4 & 5.11 & 47.5 \\
$80^{\circ} \mathrm{C}$ & 67.8 & 5.81 & 32.8 & 68.5 & 5.85 & 26.1 & 66.9 & 6.67 & 43.2 \\
$90^{\circ} \mathrm{C}$ & 64.2 & 7.96 & 34.9 & 69.4 & 5.43 & 27.0 & 64.0 & 7.89 & 42.6 \\
\hline
\end{tabular}




\subsection{Properties of Mulberry Extracts \\ (Fluorescence and Reducibility)}

Morin, isorhamnetin, kaempferol, quercetin and myricetin show fluorescence, when they form a complex with $\mathrm{Al}^{3+}$ [15]. If such the flavonols that have 3-hydroxyl and 4-carbonyl groups would be contained in the mulberry extracts, they could show fluorescence with the addition of $\mathrm{AlCl}_{3}$ into their solution. The fluorescent complexes form by the coordination of 3-hydroxyl and 4-carbonyl groups of the flavonoids to $\mathrm{Al}^{3+}$. Figure 6 shows the pictures of $\mathrm{AlCl}_{3}$, mulberry extracts and mulberry extracts/ $\mathrm{AlCl}_{3}$ solutions, which are irradiated with UV lights, of which centre wavelengths $(\lambda)$ are 312 or $365 \mathrm{~nm}$. The UV light sources are not monochromatic ones. While no light emission is observed for $\mathrm{AlCl}_{3}$ solution, mulberry extracts and mulberry extracts/ $\mathrm{AlCl}_{3}$ solutions emit fluorescent light by the UV irradiation. It is found that more intense emission from the mulberry extracts solution is obtained with $312 \mathrm{~nm}$ UV irradiation (Figure 6(b)) than with $365 \mathrm{~nm}$ one (e), and the emission light colours from the mulberry extracts $/ \mathrm{AlCl}_{3}$ solution with $312 \mathrm{~nm}$ (c) and $365 \mathrm{~nm} \mathrm{UV} \mathrm{(f)} \mathrm{irradiation} \mathrm{are} \mathrm{differ-}$ ent. The emission is naturally not observed for $\mathrm{AlCl}_{3}$ solution. The results show that the mulberry extracts may contain the flavonoids as mentioned above and they might contain also $\mathrm{Al}$ compounds or some other substances, which show fluorescence.

Then, fluorescence spectra were measured to get information on the optical properties of the mulberry extracts. Figure 7 shows 3D fluorescence excitation-emission spectra for the mulberry extracts (a) and mulberry extracts/ $\mathrm{AlCl}_{3}$ (b) solution. The small signals found the spectra are Rayleigh scattering, half Rayleigh scattering and secondary Rayleigh scattering lights, and Raman scat

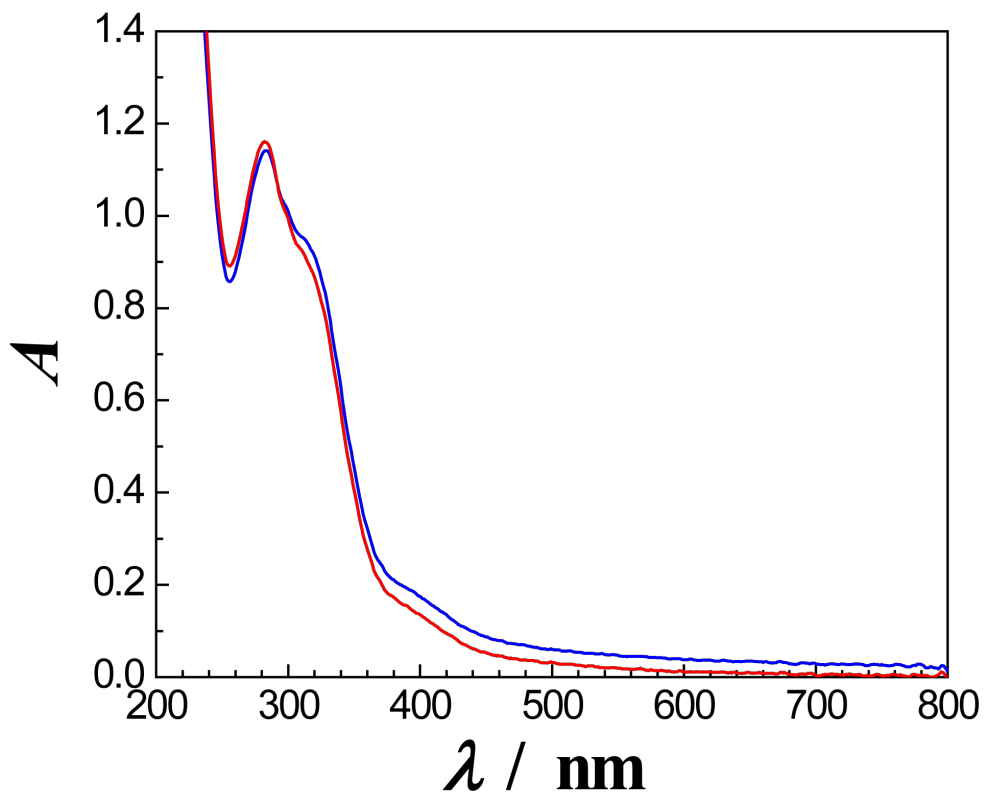

Figure 5. Absorption spectra for mulberry extracts aqueous solutions before heated (blue line) and $3 \mathrm{~h}$ after heated (red line). Conc. of mulberry extracts for each solution: $2.0 \times 10^{-2} \mathrm{wt} \%$, solution $\mathrm{pH}=6.5$. 
tering light from water [16]. A highest emission for the mulberry extracts solution is observed with $310 \mathrm{~nm}$ excitation light as seen in Figure 7(a) and the highest one for the mulberry extracts $/ \mathrm{AlCl}_{3}$ solution is detected with $310 \mathrm{~nm}$ excitation light as seen in Figure 7(b). Another second highest signal is detected for the mulberry extracts/ $/ \mathrm{AlC}_{3}$ solution with $410 \mathrm{~nm}$ excitation light. It can be said that most intensive fluorescence emission from the mulberry solutions is made with $310 \mathrm{~nm}$ excitation light. Figure 8 shows 1D fluorescence emission spectra for the the mulberry extracts (a) and mulberry extracts/ $\mathrm{AlCl}_{3}$ (b) solu-tion, which are obtained with $310 \mathrm{~nm}$ (a) and 310 and $410 \mathrm{~nm}$ (b) excitation lights, respectively. The wavelength of the most intensive emission signal is 370 $\mathrm{nm}$ for both of the solution and that of the second most intensive one for the mulberry extracts/ $\mathrm{AlCl}_{3}$ solution is $490 \mathrm{~nm}$ with $410 \mathrm{~nm}$ excitation light (red line in (b)).

The emission spectra for both of the solution with $310 \mathrm{~nm}$ excitation light are almost same. This means that the emission caused with $310 \mathrm{~nm}$ excitation light is due to fluorescent substances contained in the extracts themselves and the another emission caused with $410 \mathrm{~nm}$ excitation light is due to complexes formed from the extracts and $\mathrm{Al}^{3+}$. The fluorescence for the complexes contributes

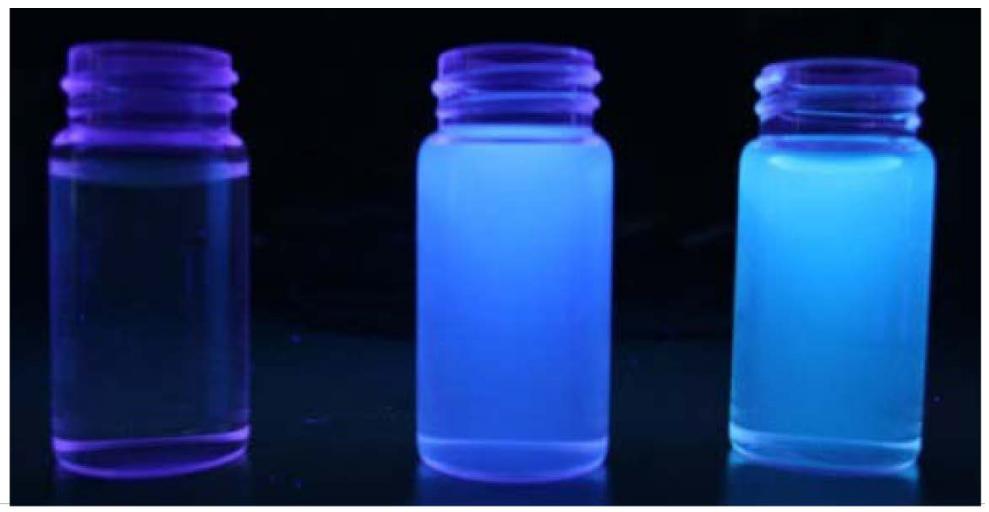

(a)

(b)

(c)

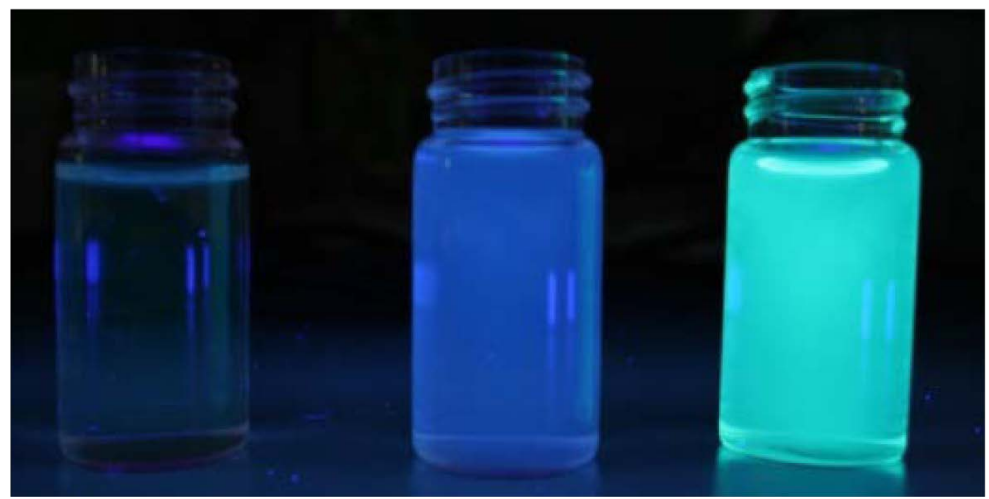

(d)

(e)

(f)

Figure 6. Photographs of $\mathrm{AlCl}_{3}$ aqueous solution (a) and (d); mulberry extracts aqueous solution (b) and (e) and mulberry extracts/ $/ \mathrm{AlCl}_{3}$ aqueous solution (c) and (f). Samples were irradiated with $312 \mathrm{~nm}$ UV lights (a)-(c) and $365 \mathrm{~nm}$ UV lights (d)-(f). 


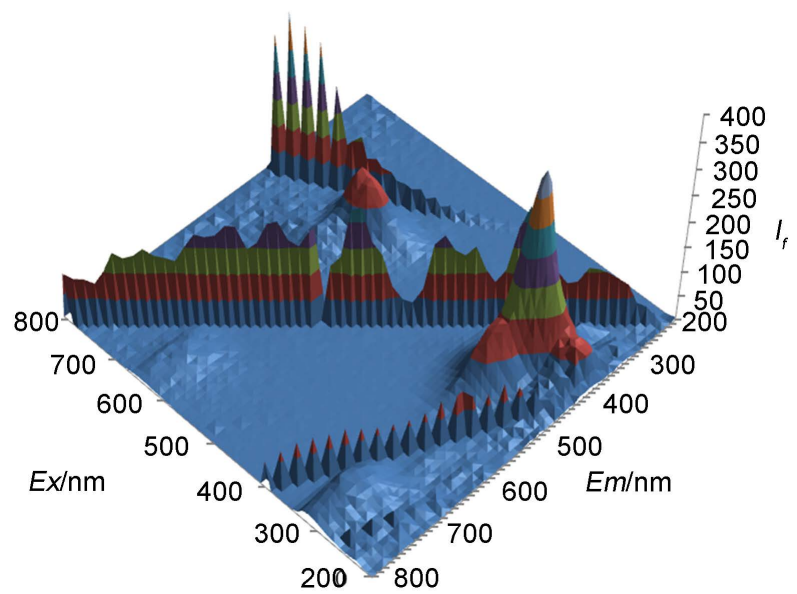

(a)

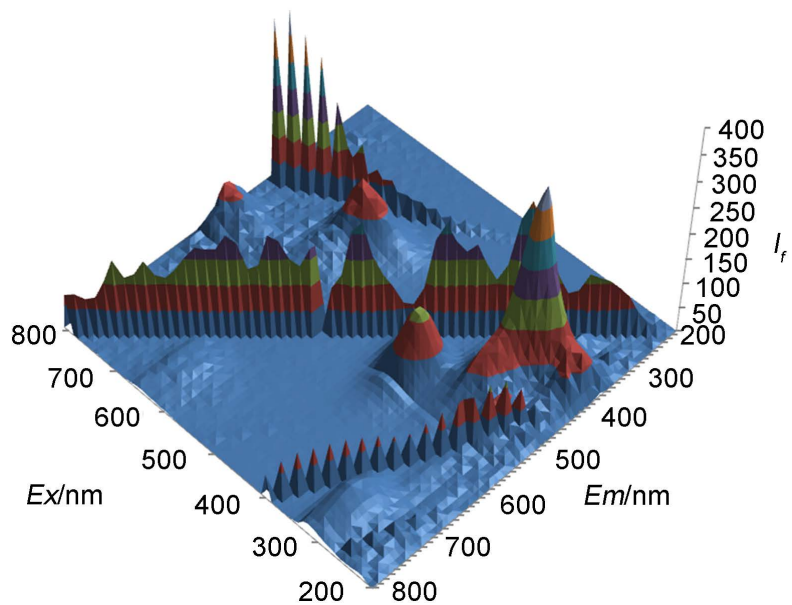

(b)

Figure 7. The 3D fluorescence excitation-emission spectra for the mulberry extracts (a) and mulberry extracts/ $\mathrm{AlCl}_{3}$ (b) aqueous solution. $E_{x}$ : excitation wavelength, $E_{m}$ : emission wavelength, $I_{\dot{f}}$ fluorescence intensity. Conc. of mulberry extracts for each solution: $1.0 \times 10^{-2} \mathrm{wt} \%$, Conc. of $\mathrm{AlCl}_{3}$ for (b): $0.050 \mathrm{M}$, solution $\mathrm{pH}=6.5(\mathrm{a}), \approx 6.5(\mathrm{~b})$.

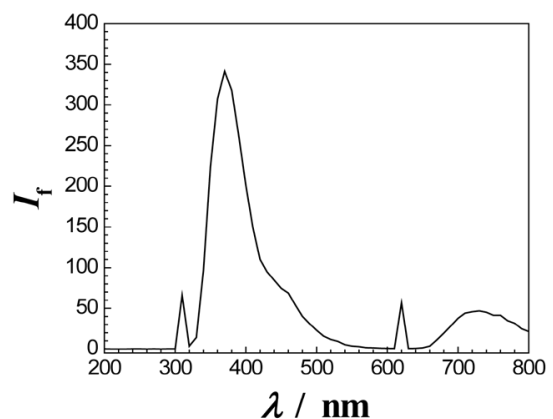

(a)

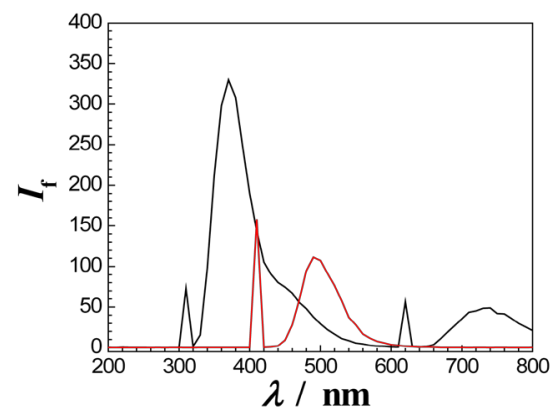

(b)

Figure 8. The 1D fluorescence emission spectra for the mulberry extracts aqueous solution irradiated with $310 \mathrm{~nm}$ light (black line) (a) and mulberry extracts $/ \mathrm{AlCl}_{3}$ aqueous solution irradiated with $310 \mathrm{~nm}$ (black line) or $410 \mathrm{~nm}$ light (red line) (b); $\lambda$ : emission wavelength, $I_{\dot{f}}$ fluorescence intensity. Conc. of mulberry extracts for each solution: $1.0 \times$ $10^{-2}$ wt $\%$, Conc. of $\mathrm{AlCl}_{3}$ for (b): $0.050 \mathrm{M}$, solution $\mathrm{pH}=6.5$ (a), $\approx 6.5$ (b). 
the colour shift observed in Figure 6(f), because the wavelength of $365 \mathrm{~nm}$ light is near to $410 \mathrm{~nm}$. In fact, the $365 \mathrm{~nm}$ light source irradiates short wavelength visible lights.

The phenolic substances contained in trees belonging to Moraceae family were studied and analyses were made [17]. It was reported that the mulberry species such as Morus (M.) alba, M. indica, M. serrata, M. laevigata and M. rubra contain morin, kaempferol, quercetin and other flavonoids or phenolic substances in their heartwoods. Therefore, morin, kaempferol or quercetin can be contained in the extracts from the branches and trunks of Morus australis and Morus lhou species used in the study.

It is expected that dyed fabrics with the mulberry extracts and mulberry extracts $/ \mathrm{AlCl}_{3}$ show fluorescence. Wool fabric was treated with (1) $\mathrm{AlCl}_{3}$ solution, (2) the mulberry extracts solution or (3) first $\mathrm{AlCl}_{3}$ solution and second the mulberry extracts solution, and the obtained fabric samples were irradiated with $365 \mathrm{~nm}$ UV light. Figure 9 shows the photographs of wool samples without and under UV light. The colours of the wool samples are almost white (original colour, Figure 9(a)), light yellowish ocher (b) or vivid yellow (c), which are treated with (1) $\mathrm{AlCl}_{3}$ solution, (2) the mulberry extracts solution or (3) $\mathrm{AlCl}_{3}$ and the mulberry extracts solutions, respectively. The mordant effects using metal compounds to modify the obtaining colour are expected for the mulberry extracts from the results. The investigation results obtained from the combination of the mulberry extracts and metal compounds will be reported by the authors.

While the wool treated with $\mathrm{AlCl}_{3}$ solution does not show fluorescence (d), mulberry extracts-dyed one (e) and $\mathrm{AlCl}_{3}$ /mulberry extracts-dyed one (f) show fluorescence. The fluorescence emission intensity of the $\mathrm{AlCl}_{3} /$ mulberry extractsdyed wool is higher than that of the mulberry extracts-dyed one. The results

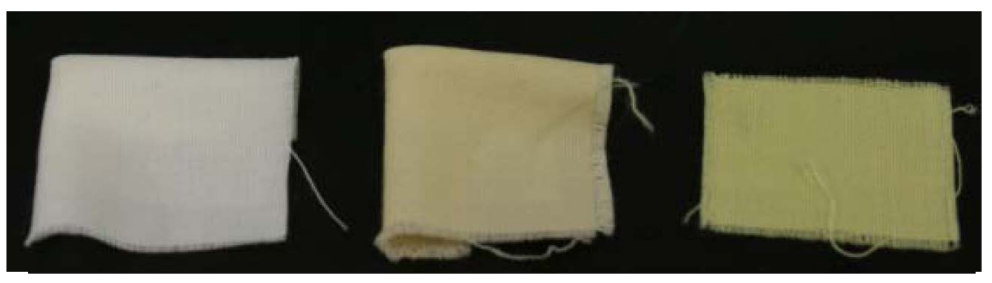

(a)

(b)

(c)

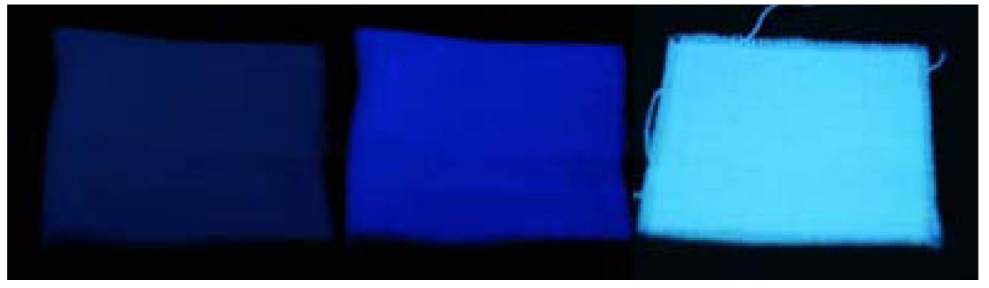

(d)

(e)

(f)

Figure 9. Photographs of wool fabrics treated with $\mathrm{AlCl}_{3}$ aqueous solution (a) and (d); with mulberry extracts aqueous solution (b) and (e) or with first $\mathrm{AlCl}_{3}$ aqueous solution and second mulberry extracts aqueous solution (c) and (f). Samples were under visible lights (a)-(c) and under $365 \mathrm{~nm}$ UV light (d)-(f). 
show the fabrics treated with the mulberry extracts solution show fluorescence and the fluorescence intensity is increased when the dyeing is combined with

$\mathrm{AlCl}_{3}$ solution and irradiation is made by UV light, of which wavelength is in the vicinity of $410 \mathrm{~nm}$ or which includes longer wavelength lights.

The results indicate that the mulberry extracts contain flavonols such as morin and quercetin as described previously.

If they contain such the flavonols, they show reducing property. It is known that the many flavonoids show antioxidant characteristic. Then, the reducibility of mulberry extracts was examined by DPPH method.

Figure 10 shows the plot of DPPH method to determine the reducibility of the mulberry extracts. The obtained $R_{\mathrm{AC}}$ value that is an index indicating reducibility, for the mulberry extracts is 16.1 . The obtained $R_{\mathrm{AC}}$ value for a standard reductant compound, DL- $\alpha$-tocopherol, under the experimental condition is 546 . The $R_{\mathrm{AC}}$ value for the mulberry extracts is smaller than that of DL- $\alpha$-tocopherol. However, the result shows that the mulberry extracts have reducing property.

The results indicate that flavonoids contained in the extracts may play an important role for the dyeing as dyestuffs. Further analytical study is needed to know the composition of mulberry extracts.

\section{Conclusion}

The wool, nylon and silk fabrics are dyed brownish and yellowish colours by the extracts from the mulberry branches and trunks, which are extracted with hot water. The obtained colours depend on the extracts concentration in the dye solution, dyeing time, dye solution $\mathrm{pH}$ and dyeing temperature. The mulberry ex-

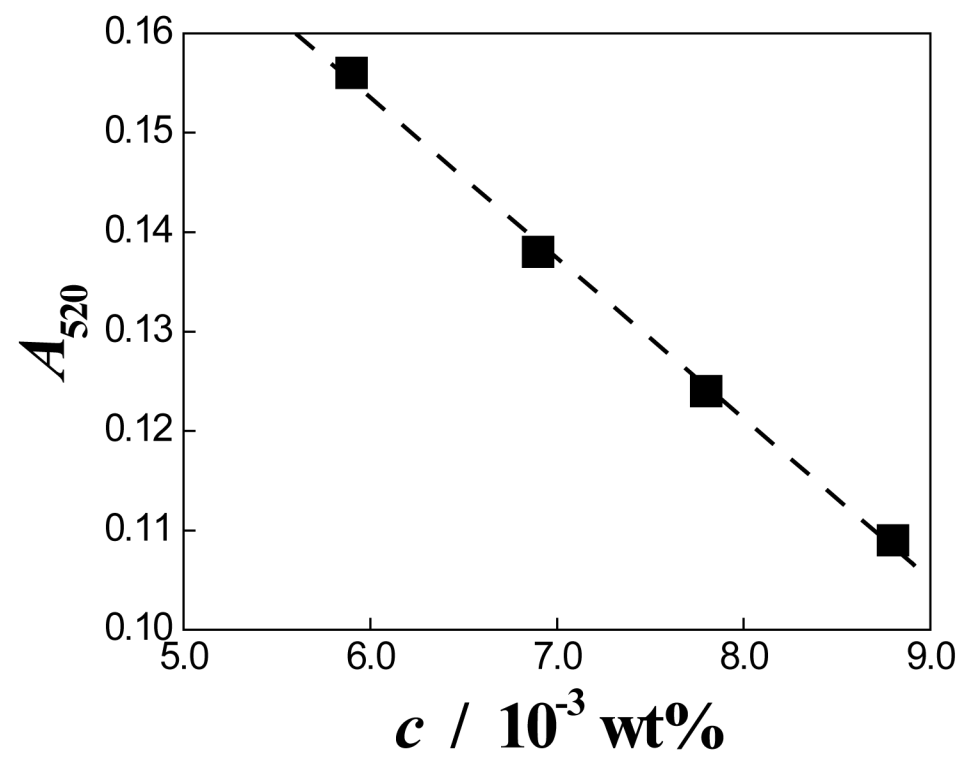

Figure 10. Plot of absorbance at $520 \mathrm{~nm}\left(A_{520}\right)$ of DPPH buffer (MES) solution mixed with mulberry extracts against the concentration of mulberry extracts $(c)$. 
tracts show fluorescence and reducing property. It is indicated that the mulberry extracts contain flavonols, which form complexes with $\mathrm{Al}^{3+}$. The wool treated with the mulberry extracts or $\mathrm{AlCl}_{3} /$ mulberry extracts shows fluorescence and the emission intensity is increased by the combination with $\mathrm{AlCl}_{3}$.

\section{Acknowledgements}

The authors wish to thank sincerely Prof. Ichida of Kyoto Institute of Technology and for his very kind supply of the mulberry branches and trunks and fruitful discussion.

\section{References}

[1] Qin, J., He, N., Wang, Y. and Xiang, Z. (2012) Ecological Issues of Mulberry and Sustainable Development. Journal of Resources and Ecology, 3, 330-339.

https://doi.org/10.5814/j.issn.1674-764x.2012.04.006

[2] Ozen, E., Yeniocak, M., Colak, M., Goktas, O. and Koca, İ. (2014) Colorability of Wood Material with Punica granatum and Morus nigra Extracts. BioResources, 9, 2797-2807. https://doi.org/10.15376/biores.9.2.2797-2807

[3] Ito, D. (1995) Ecological Studies on Light Interception and Photosynthesis of Mulberry Populations. Doctor Thesis, Kyoto University, Kyoto. (in Japanese) https://dx.doi.org/10.11501/3102678

[4] Robertson, A.R. (1977) The CIE 1976 Color-Difference Formulae. Color Research \& Application, 2, 7-11. https://doi.org/10.1002/j.1520-6378.1977.tb00104.x

[5] Commission Internationale de l'Eclairage (2007) Colorimetry-Part 4: CIE 1976 $L^{\star} a^{\star} b^{\star}$ Colour Space, CIE S 014-4/E:2007 (ISO 11664-4:2008(E)), Switzerland.

[6] Sharma, O.P. and Bhat, T.K. (2009) DPPH Antioxidant Assay Revisited. Food Chemistry, 113, 1202-1205. https://doi.org/10.1016/j.foodchem.2008.08.008

[7] Kuroda, A. (2016) Dyeing Textiles by Using Extracts from Mulberry Branch and Trunk. Master Thesis, Kyoto Institute of Technology, Kyoto, 22-36. (in Japanese).

[8] Wrolstad, R.E. (2004) Anthocyanin Pigments-Bioactivity and Coloring Properties. Journal of Food Science, 69, 419-421. https://doi.org/10.1111/j.1365-2621.2004.tb10709.x

[9] Brouillard, R., Mazza, G., Saad, Z., Albrecht-Gary, A.M. and Cheminat, A. (1989) The Copigmentation Reaction of Anthocyanins: A Microprobe for the Structural Study of Aqueous Solutions. Journal of the American Chemical Society, 111, 26042610. https://doi.org/10.1021/ja00189a039

[10] Skinner, B.G. and Vickerstaff, T. (1945) The Absorption of Acid Dyes by Wool, Silk, Casein Fibre and Nylon. Journal of the Society of Dyers and Colourists, 61, 193201. https://doi.org/10.1111/j.1478-4408.1945.tb02364.x

[11] Brouillard, R. and Dubois, J.-E. (1977) Mechanism of the Structural Transformations of Anthocyanins in Acidic Media. Journal of the American Chemical Society, 99, 1359-1364. https://doi.org/10.1021/ja00447a012

[12] Mama, G. and Brouillard, R. (1987) Color Stability and Structural Transformations of Cyanidin 3,5-Diglucoside and Four 3-Deoxyanthocyanins in Aqueous Solutions. Journal of Agricultural and Food Chemistry, 35, 422-426. https://doi.org/10.1021/jf00075a034

[13] Matsubara, T., Wataoka, I., Urakawa, H. and Yasunaga, H. (2013) Effect of Reaction $\mathrm{pH}$ and $\mathrm{CuSO}_{4}$ Addition on the Formation of Catechinone Due to Oxidation of (+)-Catechin. International Journal of Cosmetic Science, 35, 362-367. 
https://doi.org/10.1111/ics.12051

[14] Vickerstaff, T. (1954) The Physical Chemistry of Dyeing. Chapter 5, Oliver and Boyd, London.

[15] Hollman, P.C.H., van Trijp, J.M.P. and Buysman, M.N.C.P. (1996) Fluorescence Detection of Flavonols in HPLC by Postcolumn Chelation with Aluminum. Analytical Chemistry, 68, 3511-3515. https://doi.org/10.1021/ac960461w

[16] Lakowicz, J.R. (2006) Principles of Fluorescence Spectroscopy. 3rd Edition, Springer, Berlin. https://doi.org/10.1007/978-0-387-46312-4

[17] Venkataraman, K. (1972) Wood Phenolics in The Chemotaxonomy of The Moraceae. Phytochemistry, 11, 1571-1586.

Submit or recommend next manuscript to SCIRP and we will provide best service for you:

Accepting pre-submission inquiries through Email, Facebook, LinkedIn, Twitter, etc. A wide selection of journals (inclusive of 9 subjects, more than 200 journals)

Providing 24-hour high-quality service

User-friendly online submission system

Fair and swift peer-review system

Efficient typesetting and proofreading procedure

Display of the result of downloads and visits, as well as the number of cited articles Maximum dissemination of your research work

Submit your manuscript at: http://papersubmission.scirp.org/

Or contact ajps@scirp.org 